Article

\title{
In Vitro Bonding Performance of Modern Self-Adhesive Resin Cements and Conventional Resin-Modified Glass Ionomer Cements to Prosthetic Substrates
}

\author{
Encarna Piquer Maño ${ }^{1}$, Rafael Marco Algarra ${ }^{1}$, Amr Fawzy $^{2}{ }^{\mathbb{C}}$, Vicente C. B. Leitune ${ }^{3}{ }^{\circ}$, \\ Fabrício M. Collares ${ }^{3}$ (D), Victor Feitosa ${ }^{4}$ id and Salvatore Sauro ${ }^{1, *(D)}$ \\ 1 Departamento de Odontología, Facultad de Ciencias de la Salud, Universidad CEU-Cardenal Herrera, \\ C/Del Pozo (s/n), Alfara del Patriarca, 46115 Valencia, España; encarna.piquer@uchceu.es (E.P.M.); \\ rafael.marco@uchceu.es (R.M.A.) \\ 2 UWA Dental School, University of Western Australia, 17 Monash Avenue, Nedlands WA 6009, Australia; \\ amr.fawzy@uwa.edu.au \\ 3 Dental Materials Laboratory, School of Dentistry, Federal University of Rio Grande do Sul, Ramiro Barcelos, \\ 2492, Rio Branco, Porto Alegre, RS 90035-003, Brazil; vicente.leitune@ufrgs.br (V.C.B.L.); \\ fabricio.collares@ufrgs.br (F.M.C.) \\ 4 Paulo Picanço School of Dentistry, 900 Joaquim Sá Street, Fortaleza 60325-218, Brazil; \\ victor.feitosa@facpp.edu.br \\ * Correspondence: salvatore.sauro@uchceu.es; Tel.: +34-96-136-90-00 (ext. 64905)
}

Received: 18 October 2020; Accepted: 16 November 2020; Published: 18 November 2020

check for updates

\begin{abstract}
This study aimed at evaluating the shear bond strength (SBS) of modern self-adhesive resin cements and resin-modified glass ionomer cements applied to different prosthetic substrates. Zirconia, lithium-disilicate glass-ceramic and a noble metal alloy were used as bonding substrates. They were all sand-blasted with alumina, while LD was further etched with $9.6 \%$ hydrofluoric acid (10 s). A light-curing resin-modified glass ionomer cement (3M-GIC: Ketac Cem Plus) and a self-curing resin-modified glass ionomer cement (GC-GIC: FujiCEM 2) were compared to self-adhesive resin cements (PAN: Panavia SA Universal) and (3M-RES: Rely X Unicem 2). Ten specimens for each substrate were produced and up to five cylinders of each cement were bonded to each substrate. The shear bond strength (SBS) was evaluated after $24 \mathrm{~h}$ or after thermocycling (TC) aging (5000 cycles). The data was statistically analysed by two-way ANOVA and Student-Newman-Keuls test $(\alpha=0.05)$. Failure modes were analysed through stereoscopic microscopy. The greatest SBS was attained with PAN, whilst 3M-GIC showed the lowest SBS and failed prevalently in adhesive mode. No difference in SBS was observed between GC-GIC and 3M-RES. After TC aging, all cements showed significant drop $(p<0.05)$ in SBS, but PAN showed the greatest SBS. Reliable bond strength to prosthetic substrates can be achieved with specific universal resin-luting cements and may be an alternative to glass ionomer cements when luting alloy substrates.
\end{abstract}

Keywords: self-adhesive cements; resin cements; resin-modified glass ionomer cements; shear bond strength; thermocycling

\section{Introduction}

Nowadays, a great assortment of prosthetic materials is available on the market such as silica-based ceramics (e.g., feldspathic, leucite-reinforced and lithium disilicate ceramics) and polycrystalline silica-free ceramics (e.g., zirconia and alumina). Moreover, noble metal alloys based on Ag-Pd-Cu-Au are widely used for cast restorations (e.g., porcelain-fused-to-metal or full metal crowns and bridges) 
as an alternative to ISO type-III or -IV alloys containing gold; in some countries such as Japan, insurances cover the cost for such alloys for restorative and prosthodontic treatments [1,2].

Luting procedures represent a crucial step in restorative dentistry so as to achieve long-lasting performance by indirect restorations. Nowadays, a large number of luting cements and prosthetics substrates are available on the market with specific biological, physicochemical and aesthetic properties [1]. Luting cements are generally classified as temporary and permanent materials. This first class of materials, also known as "provisional luting cements" can be identified in two main types: calcium hydroxide and zinc-oxide cements. Conversely, permanent or "definitive" luting cements include those materials characterised by adhesive properties to different dental and/or prosthetic substrates. For instance, this latter class of materials can be classified into low (zinc phosphate and silicate cements), medium (polycarboxylate cement) or high (glass ionomer and resin cements) strength luting materials. In particular, the high strength luting cements, which can set either via chemical/self-activation, light-curing or dual-activation process $[2,3]$ were investigated in this research project. However, high strength resin cements are also categorised based on the bonding strategy employed for their application: (i) luting resin cements; (ii) self-adhesive resin cements. Conventionally, luting resin cements require the application of a primer or a surface pretreatment of the bonding substrates. Conversely, self-adhesive resin cements are advocated for direct bonding on substrates, as the retention is provided by specific adhesive functional monomers (i.e., 10-MDP) and/or silanes contained within the formulation of such materials [3]. They represent the most innovative simplified class of resin cements, which rapidly reached a great popularity due to their user-friendly clinical uses. Indeed, substrate pretreatments through acid etching and/or application of adhesive primers would not be necessary anymore [4,5], although general practitioners are still confused regarding the bonding protocols when employing such materials [6].

It is important to highlight that when using such permanent luting cements, in particular those reinforced with resin (e.g., resin-modified glass ionomer cements and resin-based cements), one can have numerous clinical advantages, in primis, a reduction of secondary caries due to low cement solubility, with consequent reduction of the risk for pulp harm [7-9]. Moreover, it has been advocated that when cast post and-core build-ups are cemented using such materials, it is possible to attain an important drop of the risk for root fractures $[9,10]$. It was also reported that the use of adhesive resin-based cements may increase the fracture resistance and extend the durability of aesthetic ceramic and composite indirect restorations [11-13].

However, it is a common view that the accomplishment of an ideal bonding to both dental [14-16] and prosthesis's surfaces [17-21], some specific pretreatments should be employed. The effectiveness of surface pretreatments depends not only on the operators' skills and experience but also on the quality of specific equipment, along with their sensitive manipulation, used to accomplish such procedures. During the last ten years, a rapid development of new resin cements with specific properties has been observed, which may allow clinicians to provide adequate bond strength but with simplified and user-friendly surface treatments [22-24]. Nevertheless, there is limited evidence on the bond strength of newer self-adhesive resin cements compared to that of conventional or self-adhesive resin-based and resin-modified glass ionomer cements (RMGICs) when bonded to a variety of prosthetic substrates.

Thus, the purpose of this in vitro study was to investigate the bonding performance and the failure mode of modern universal self-adhesive resin cements and conventional resin-modified glass ionomer cements applied to different prosthetic substrates. This aim was accomplished by assessing the shear bond strength (SBS) of the tested self-adhesive cements applied to zirconia, lithium disilicate or a noble metal alloy (Ag-Pd-Cu-Au) before and after thermocycling aging (5000 cycles). The first null-hypothesis of this study was that there would be no differences in bonding performance between tested cements when applied on different substrates. The second null-hypothesis was that the thermocycling aging would induce no significant reduction on SBS of the tested cements when applied on different substrates. 


\section{Materials and Methods}

\subsection{Specimen Preparation}

Three different prosthetic substrates were employed in this experimental project: (1): Zirconia (KAT: Katana HT blocks, Kuraray Medical Co., Ltd. Tokyo, Japan); (2): Lithium disilicate glass-ceramic (LD: IPS e.max CAD blocks, Ivoclar Vivadent, Schaan, Liechtenstein); (3): Silver-gold alloy [AU: Econolloy Au casting alloy (Ag 43.0\%, Au 33.0\%, Pd 14.8\%, In 8.0\%, Pt 1.0\%, Ir/ $\mathrm{Nb} 0.2 \%$ ), DeguDent, Dentsply DeTrey GmbH, Konstanz, Germany]. Rectangular specimens (20.0 mm in length, $10.0 \mathrm{~mm}$ width and $5.0 \mathrm{~mm}$ in thickness) of KAT $(\mathrm{n}=10 /$ cement $)$ and $\mathrm{LD}(\mathrm{n}=10 /$ cement $)$ were cut using a low-speed microtome (Remet evolution, REMET, Bologna, Italy) equipped with a diamond-embedded saw, under water irrigation. Subsequently these specimens were processed in a dental prosthetic technician lab at specific temperature ranges as per manufacturer's instructions. Ingots of AU alloy were used according to the manufacturer's instructions to cast a total of ten blocks ( $15.0 \mathrm{~mm}$ in length, $10.0 \mathrm{~mm}$ in width and $3.0 \mathrm{~mm}$ thickness). All the specimens from each prosthetic group were polished using abrasive $\mathrm{SiC}$ paper (\#320-grit) in order to obtain a standardised flat and smooth surface in all the specimens. Subsequently, these were sand-blasted at $5 \mathrm{~mm}$ distance for $1 \mathrm{~min}$ using the $59-\mu \mathrm{m}$ aluminium oxide at 5-bar pressure (Aquacare Velopex, Medivance Instruments Ltd., London, UK). The specimens were ultrasonicated in a solution of $96 \%$ ethanol and distilled water (ratio 1:1) for $5 \mathrm{~min}$ in order to remove any residual presence of aluminium oxide. The lithium-disilicate specimens were submitted to a further surface treatment, using 9.6\% hydrofluoric acid (Pulpdent, Watertown, MA, USA) for $10 \mathrm{~s}$. These specimens were then thoroughly rinsed and treated in the ultrasonic bath as in the case of KAT. Two further specimens were created for each substrate and processed for ultramorphology analysis through Scanning Electron Microscopy (SEM) before and after surface treatments (i.e., control, sand-blasting and/or acid-etching procedures). Such specimens were finally gold-sputter-coated and imaged using field-emission scanning electron microscopy (FE-SEM S-4100; Hitachi, Wokingham, UK) at $10 \mathrm{kV}$ and a working distance of $15 \mathrm{~mm}$.

\subsection{Shear Bond Strength Evaluation (SBS)}

A light-curing resin-modified glass ionomer cements (3M-GIC: Ketac Cem Plus, 3M ESPE, St Paul, MN, USA) and a self-curing resin-modified glass ionomer cement (GC-GIC: FujiCEM 2, GC Corp., Tokyo, Japan) were used in this study, along with two modern self-adhesive resin cements (PAN: Panavia SA Universal, Kuraray, Tokyo, Japan; 3M-RES: Rely X Unicem 2 Automix 3M ESPE, MN, USA). All cements were handled as per manufacturer's instructions and applied onto the specimens previously created and pretreated with air-abrasion and/or acid etching. Each prosthetic substrate was bonded with the tested cement using a customised plastic mould for delimitation, with a cylindrical opening to be placed on top of the prepared substrate (ULTRADENT Inc., Salt Lake City, UT, USA). Ten specimens per group $(n=10)$ were used, and up to five cylinders were bonded to every single ceramic/metal specimen (Figure 1). Each cement was applied and agitated for $5 \mathrm{~s}$ using a dental probe to avoid air bubble formations, followed by application of a standardised constant force of $0.454 \mathrm{~kg}$ using a custom-made device for $30 \mathrm{~s}$. Thereafter, the specimens created with light-curing cements were photo-activated for $30 \mathrm{~s}$ using a Radii-Cal LED curing light (SDI, Victoria, Australia) with a standard mode and energy output of $1200 \mathrm{~mW} / \mathrm{cm}^{2}$. In the case of the self-cured resin-modified cement (GC-GIC), this was left undisturbed in air for $10 \mathrm{~min}$ to achieve a proper setting reaction. Upon removal of the cement cylinders from the mould, any excess cement was removed using a composite spatula. Before the test, the ceramic/resin cylinder interfaces were checked under an optical microscope 20× (Olympus, Tokyo, Japan) for bonding defects. The cement cylinders that showed apparent interfacial gap formation, bubble inclusion or any other defects were excluded and replaced by fresh ones. The bonded specimens were then placed in a plastic container along with paper soaked in distilled water and stored at $37^{\circ} \mathrm{C}$ for $24 \mathrm{~h}$. Half of the specimens from each group were tested after $24 \mathrm{~h}$ (baseline) incubation at $37^{\circ} \mathrm{C}$ in wet environment (distilled water) for SBS, while the other half 
part of the specimens was first submitted to thermocycling aging with 5000 thermocycles $\left(5-55{ }^{\circ} \mathrm{C}\right)$ in distilled water. The SBS evaluation was accomplished with a shear bond testing machine (Bisco, Schaumburg, IL, USA) at a crosshead speed of $0.5 \mathrm{~mm} / \mathrm{min}$ until the failure occurs. Maximum stress values in Newton $(\mathrm{N})$ were obtained. The values were converted into megapascal (MPa) by considering bonding surface area of the resin cements $\left(4.45 \mathrm{~mm}^{2}\right)$. The specimens unit was the prosthetic substrate.

$$
[\mathbf{M P a}]=\frac{[\mathbf{N}] \text { Force }}{\left[\mathrm{mm}^{2}\right] \text { Area }}
$$

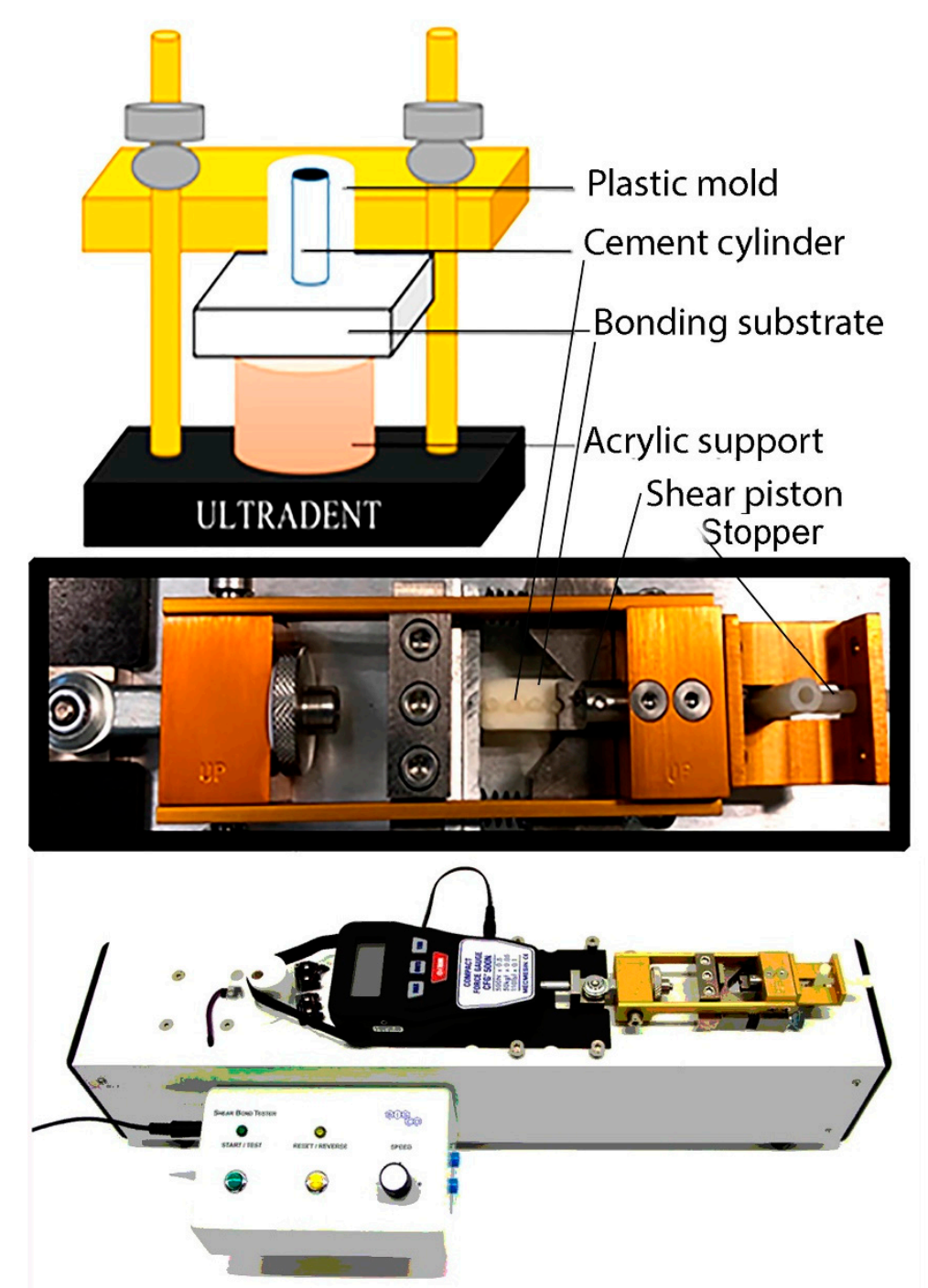

Figure 1. Schematic representation of the specimen preparation and shear bond strength test.

Data were analysed statistically by two-way ANOVA including interactions between factors, using SBS as a dependent variable. Type of cement and aging method ( $24 \mathrm{~h}$ vs. TC) were considered as independent variables. Post-hoc multiple comparisons were performed using the Student-Newman-Keuls test. Statistical significance was set at $\alpha=0.05$.

\subsection{Failure Mode Analysis}

After shear bond strength testing, the fractured surfaces of all the specimens with and without thermocycling aging were analysed using 30× magnification stereoscopic microscopy. Failure modes were classified as adhesive failure (A), cohesive failure (C) or mixed failure (M) by examining the 
fracture surfaces. In details, adhesive failure was determined when debonding occurred at the interface between cement and either disk surface. Cohesive failure was observed when the fracture occurred within the cement layer. Mixed failure was observed when the specimen exhibited a combination of adhesive and cohesive failures.

\section{Results}

Shear bond strength mean and standard deviation values $( \pm \mathrm{SD})$ are expressed in MPa in Table 1 . Type of cement and aging (thermocycling) influenced the SBS results $(p<0.01)$. Interactions between factors were also significant $(\mathrm{F}=78.05 ; p<0.05)$. In brief, the use of alumina for sand-blasting procedures increased the roughness of the zirconia surface (Figure $2 \mathrm{~A}, \mathrm{~B})$. The baseline $(24 \mathrm{~h})$ results showed that the greatest bond strength $(p<0.05)$ in KAT zirconia was attained when using the universal self-adhesive resin luting cement PAN (20.3 MPa), whilst the RMGIC luting cement 3M-GIC showed the lowest SBS values (2.5 MPa); in this latter group, all the specimens failed in the adhesive mode. Conversely, $25 \%$ of specimens created on zirconia with PAN failed in the mixed mode and $75 \%$ in adhesive mode. There was no significant difference $(p>0.05)$ between GC-GIC and 3M-RES in terms of bond strength to KAT; both of them failed prevalently in adhesive mode ( $>90 \%)$. After thermocycling aging (TC), all the cements showed a significant drop $(p<0.05)$ in bond strength when compared to their relative groups at $24 \mathrm{~h}$ (baseline results). However, also in this case, the greatest bond strength $(p<0.05)$ was attained by PAN (11.3 MPa), whilst the 3M-GIC had the lowest values $(0.7 \mathrm{MPa})$. All groups failed prevalently in adhesive mode after TC, and only PAN showed $5 \%$ of the specimens that failed in the mixed mode. The situation was quite different in lithium disilicate ceramic (LD) as the baseline values obtained by all the tested cements were higher than those observed in any other prosthetic substrate. Indeed, the use of HF etchant, subsequent to air-abrasion pretreatment, caused the removal of the glass phase with consequent exposure of lithium disilicate crystals (Figure 2C,D). In terms of bond strength, once again, the greatest bond strength $(p<0.05)$ was attained with PAN $(29.4 \mathrm{MPa})$, while the 3M-GIC showed the lowest SBS values (6.5 MPa). The 3M-GIC failed in the adhesive mode, while $30 \%$ of the specimens created with PAN failed in the mixed mode. In addition, the resin luting cement 3M-RES presented SBS values significantly $(p<0.05)$ higher $(18.1 \mathrm{MPa})$ than the SBS values obtained with the resin-modified glass ionomer cement GC-GIC (13.6 MPa); these two groups showed respectively $15 \%$ and $10 \%$ of specimens debonded in mixed mode during SBS testing. After thermocycling aging (TC) all the cements showed a significant drop $(p<0.05)$ in SBS bond strength compared to baseline results at $24 \mathrm{~h}$. However, the greatest bond strength $(p<0.05)$ was attained by PAN $(13.4 \mathrm{MPa})$, whilst the 3M-GIC had the lowest values (0.7 MPa). All groups failed prevalently in adhesive mode after TC, and only PAN showed $5 \%$ of the specimens that debonded in the mixed mode during SBS testing. Between the two RMGIC luting cements used in this study, GC-GIC (4.1 MPa) showed significant greater $(p<0.05)$ SBS values compared to 3M-GIC $(1.5 \mathrm{MPa})$ and both of them failed totally in adhesive mode. There was a significant difference $(p<0.05)$ between the SBS values of PAN $(29 \mathrm{MPa})$ and those obtained with the 3M-RES (18.1 MPa). 
Table 1. Mean \pm SD of the SBS (MPa) at $24 \mathrm{~h}$ and after thermocycling (TC) of the tested cements to different substrates (KAT: zirconia; LD: Lithium disilicate; AU: gold alloy). Failure pattern is represented as percentual (adhesive/mix/cohesive).

\begin{tabular}{|c|c|c|c|c|c|c|}
\hline & KAT & KAT & LD & LD & AU & $\mathbf{A U}$ \\
\hline & $24 \mathrm{~h}$ & TC & $24 \mathrm{~h}$ & TC & $24 \mathrm{~h}$ & TC \\
\hline 3M-GIC & $\begin{array}{c}2.5 \pm 1.1^{\mathrm{A} 1} \\
(100 / 0 / 0)\end{array}$ & $\begin{array}{c}0.7 \pm 0.6^{\mathrm{A} 2} \\
(100 / 0 / 0)\end{array}$ & $\begin{array}{c}6.5 \pm 3.5^{\mathrm{A} 1} \\
(100 / 0 / 0)\end{array}$ & $\begin{array}{c}1.5 \pm 1.6^{\mathrm{A} 2} \\
(100 / 0 / 0)\end{array}$ & $\begin{array}{c}5.2 \pm 2.1^{\mathrm{A} 1} \\
(100 / 0 / 0)\end{array}$ & $\begin{array}{c}1.9 \pm 1.4^{\mathrm{A} 2} \\
(100 / 0 / 0)\end{array}$ \\
\hline GC-GIC & $\begin{array}{c}7.5 \pm 4.5^{\mathrm{B} 1} \\
(95 / 5 / 0)\end{array}$ & $\begin{array}{c}2.5 \pm 1.9^{\text {В2 }} \\
(100 / 0 / 0)\end{array}$ & $\begin{array}{c}13.6 \pm 2.1^{\mathrm{B} 1} \\
(90 / 10 / 0)\end{array}$ & $\begin{array}{c}4.1 \pm 2.1^{\mathrm{B} 1} \\
(100 / 0 / 0)\end{array}$ & $\begin{array}{c}6.6 \pm 2.7^{\mathrm{A} 1} \\
(93 / 7 / 0)\end{array}$ & $\begin{array}{c}3.2 \pm 1.8^{\mathrm{AC} 2} \\
(100 / 0 / 0)\end{array}$ \\
\hline 3M-RES & $\begin{array}{c}8.2 \pm 2.9^{\mathrm{B} 1} \\
(90 / 10 / 0)\end{array}$ & $\begin{array}{c}4.1 \pm 2.9^{\text {B2 }} \\
(100 / 0 / 0)\end{array}$ & $\begin{array}{c}18.1 \pm 8.9^{C 1} \\
(85 / 15 / 0)\end{array}$ & $\begin{array}{c}7.2 \pm 4.1^{C} 1 \\
(100 / 0 / 0)\end{array}$ & $\begin{array}{c}0.2 \pm 0.1^{\mathrm{B} 1} \\
(100 / 0 / 0)\end{array}$ & $\begin{array}{c}0.0 \pm 0.0^{\mathrm{B} 2} \\
(100 / 0 / 0)\end{array}$ \\
\hline PAN & $\begin{array}{c}20.3 \pm 5.7^{1 C} \\
(75 / 25 / 0)\end{array}$ & $\begin{array}{c}11.3 \pm 3.9^{C 2} \\
(95 / 5 / 0)\end{array}$ & $\begin{array}{c}29.4 \pm 5.5^{\mathrm{D} 1} \\
(70 / 30 / 0)\end{array}$ & $\begin{array}{c}13.4 \pm 6.1^{\mathrm{D} 1} \\
(95 / 5 / 0)\end{array}$ & $\begin{array}{c}11.9 \pm 5.1^{C 1} \\
(100 / 0 / 0)\end{array}$ & $\begin{array}{c}4.3 \pm 3.2^{\mathrm{AC} 2} \\
(100 / 0 / 0)\end{array}$ \\
\hline
\end{tabular}

3M-GIC: Ketac Cem Plus; GC-GIC: CG FujiCEM 2; PAN: Panavia SA Universal; 3M-RES: Rely X Unicem 2 Automix. The same letter indicates no differences in the same column. $(p>0.05)$. The same number indicates no differences in the same row for the same cement ( $24 \mathrm{~h}$ vs. thermocycling TC) $(p>0.05)$.
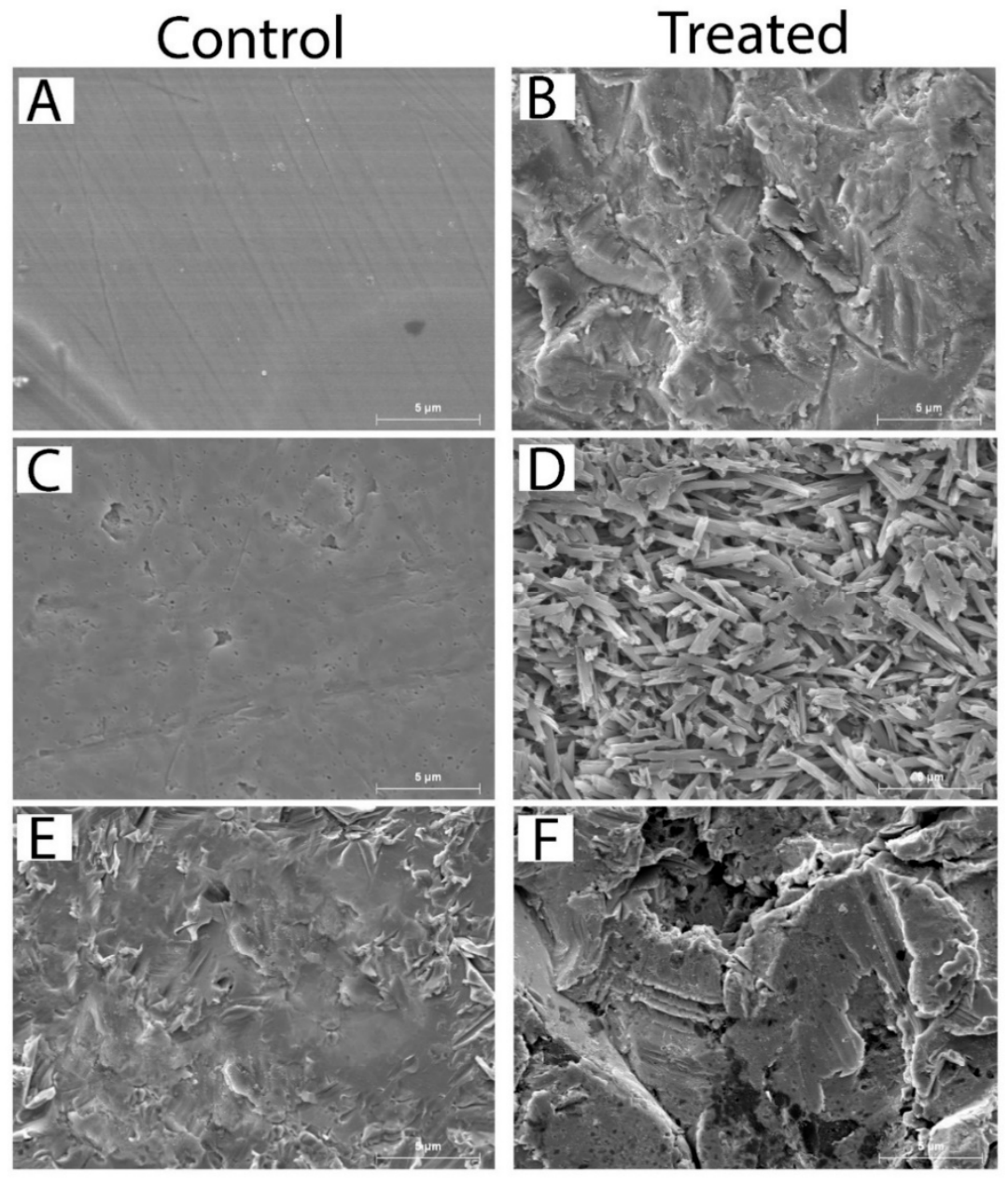

Figure 2. SEM micrographs of the bonding substrates (KAT: zirconia; LD: Lithium disilicate; AU: gold alloy) before and after surface pretreatment. Smooth and flat surface of the KAT after polishing (A), and after sandblasting (B). LD before surface treatment (C), and sandblasting followed by etching using hydrofluoric acid at 9.6\% (D). Lithium crystals and the presence of microretentions within such a mineral network could be observed (D). AU surface after polishing with the SiC carbide paper (E). After sandblasting procedures there was a clear increase in roughness and microretentions (F). 
Regarding the SBS of the tested cements in AU specimens, the surface of the specimens after air-abrasion with alumina appeared rougher (Figure 2F) than the control specimens (Figure 2E). Once again, the greatest SBS bond strength $(p<0.05)$ was attained by PAN $(11.9 \mathrm{MPa})$, whilst the resin luting cement $3 \mathrm{M}-\mathrm{RES}$ had the lowest bond strength (0.2 MPa). The two RMGIC cements used in this study showed comparable results ( $p>0.05$ ) (3M-GIC: $5.2 \mathrm{MPa}$; GC-GIC: 6.6 MPa). The specimens in all groups failed in the adhesive mode, at $24 \mathrm{~h}$ and after TC. However, all the tested cements showed a significant drop $(p<0.05)$ in SBS values compared to their baseline groups at $24 \mathrm{~h}$. All specimens created using the cement 3M-RES prefailed in adhesive mode before performing the SBS test, while the 3M-GIC cement showed very low SBS values (1.9 MPa). There was no significant difference between SBS of GC-GIC and PAN $(p>0.05)$.

\section{Discussion}

In the current in vitro study, important outcomes were obtained when analysing the bonding performance of two universal self-adhesive resin cements and two resin-modified glass ionomer cements applied to zirconia, lithium disilicate or a noble metal alloy before and after thermocycling aging.

However, it is important to anticipate before discussing such results that the method of evaluation and interpretation of the bond strength in vitro are occasionally criticised, but unfortunately there is still no substitutive methodology that may allow the assessment of the bonding performance of adhesive materials with similar overall efficiency (e.g., laboratory time and costs) [25]. The main issues arise usually when using common methods for the evaluation of shear bond strength, and in fact these are characterised by a large number of cohesive failures during the test [26]. However, the use of specimens with reduced size results in a drastic decrease of cohesive failure; that is exactly what was observed in the results of the current study (Table 1). A possible account for such outcomes may be associated to the rounded morphology of the bonding interface, as a proper distribution of the testing stress likely occurred along the bonding interface. Moreover, the experimental setup, which required no cutting or trimming procedures of the specimens, prevented undesirable fracture of the specimens before the bond strength test [27].

It is clear that the in vitro research is essential to envisage the complex clinical conditions involved in a possible real oral scenario, which usually compromises the durability of dental restorations. Therefore, in vitro aging strategies contribute to understand the processes involved in their degradation and to find some technical conciliations to delay this occurrence [28]. Thermocycling ageing is a typical strategy where specimens are immersed in water baths at different temperatures between standardised intervals of time [29]. This method is employed to simulate in in vitro studies the thermal changes induced by food and drinks daily in people and could increase interfacial degradation in short storage time [30]. In the present study, thermocycling reduced bond strength in almost all groups, indicating an important interface degradation.

The establishment of a reliable bonding to zirconia with a proper marginal integrity along the interface tooth-cement-ceramic remains an actual matter, attributable to the inert characteristic of the zirconia, as well as to the difficulty in generating consistent micromechanical retentions along its surfaces [31,32]. However, several researchers have advocated that the use of alumina $\left(\mathrm{Al}_{2} \mathrm{O}_{3}\right)$ during sandblasting/air-abrasion procedures can increase the bond strength of luting cements to zirconia $[33,34]$. Indeed, our results have shown that after sand-blasting with alumina, there was an apparent increase of micromechanical retentions on the surfaces of the specimens made of zirconia (KAT). The current study also showed that the modern universal self-adhesive resin luting cement PAN obtained at $24 \mathrm{~h}$ (baseline) the greatest bond strength in KAT, with $25 \%$ of specimens failed in the mixed mode during the SBS test. Whilst the lowest values were observed with the RMGIC luting cement 3M-GIC, with all the specimens failing in the adhesive mode. Pretty low bond strength was also observed with the other universal self-adhesive resin luting cement 3M-RES, which presented no significant difference compared to the GC-GIC; both cements fractured during bond strength testing prevalently in adhesive mode. 
Although RMGIC does not contain any phosphate-ester monomer, such as 10-methacryloyloxydecyl-dihydrogen-phosphate (MDP), this does not prevent them from creating a chemical and mechanical bonding to zirconia [35]. It has been advocated that the polyalkenoic acid polymers contained in such materials can react with metal oxides. The current results are in agreement with previous studies that showed higher bond strengths of resin-based self-adhesive cements compared to RMGIC when bonded to a variety of prosthetic substrates such as noble and non-noble alloys, zirconia and other types of glass-based ceramics [36,37]. Further studies [38-40] verified how resin-based materials containing MDP have the ability to create a strong bond strength to zirconia; such a high bond strength to zirconia may be attributed to a chemical reaction between MDP with zirconium oxide [41,42]. Some studies confirmed such a chemical interaction between MDP and zirconia [43] through contact-angle measurements, secondary ion mass spectrometry (TOF-SIMS) [44] and Fourier transform infrared spectroscopy $[45,46]$.

In order to explain the difference in bond strength obtained between 3M-GIC and GC-GIC, it is possible to hypothesise that resin-modified glass ionomer cements that set exclusively through acid-base reaction may present better bonding performance of some light-curing RMGIC; this latter class of materials seems to be affected by a sort of inhibition of the setting reaction caused by some incompatibility at early phases of setting $[47,48]$. Moreover, it was suggested that the RMGIC acid-base reaction continues overtime if undisturbed, so producing greater chemical interaction with the substrate (i.e., maturation), which may result in enhanced bonding performance at $24 \mathrm{~h}[49,50]$

The results of the current study also showed that after TC aging, all the tested cements showed a significant drop in bond strength and all of them failed in the adhesive mode. One of the reasons why there is such a reduction in bond strength may be attributed to a mismatch between the coefficient of thermal expansion of the prosthetists substrates and the cements [51]. Furthermore, a possible hydrolytic degradation of the ceramic-cement interface may have also occurred and caused a drastic reduction of the bond strength in all cements $[52,53]$

However, the self-adhesive resin cement PAN had the greatest bond strength between all groups. Usually, the sand-blasting procedures performed with alumina improves the immediate adhesion of cements containing MDP or those that require a preapplication of a MDP primer, but after thermocycling a significant drop in bond strength is often observed [54,55].

The results obtained with the PAN cement are in accordance with the those of Nagaoka et al., [56], who demonstrated that in presence of a great amount of MDP there may be more chemical interaction among different MDP molecules through intermolecular hydrogen bonding with zirconia, as well as with other $\mathrm{P}=\mathrm{O}$ groups of adjacent MDP molecules. Indeed, these outcomes are associated to the unique composition of such a modern self-adhesive cement; PAN seems to have higher amount of MDP compared to any other current commercial self-adhesive cements, including the 3M-RES cement tested in the current study [57].

It is well known that the sandblasting pretreatment may decontaminate the surface of the lithium disilicate ceramic and improve the overall bonding performance of several luting cements [58-60]. Moreover, etching procedures with hydrofluoric acid (HF) can selectively dissolves the glass matrix and crystals substrate, so creating important microretentions on the surfaces [61]. A study of Lise et al., [62] demonstrated that a self-adhesive cement bonded on a sand-blasted surfaces of a lithium disilicate ceramic without previous HF etching had very poor bonding performance. Conversely, the same authors showed that such bonding performance could be improved when using HF etching. This is the main reason why in the current study the LD ceramic was both sand-blasted and then etched with HF; further several studies reported that the only use of sand-blasting performed using $50 \mu \mathrm{m}$ alumina, without any following HF etching step, may cause a drop in bond strength $[63,64]$. In particular, Guarda et al. [65], reported that when LD was etched using 10\% HF higher bond strength values were observed compared to when using sandblasting alone. Hereafter, it was decided in this study to use a standardised sandblasting procedure with alumina for all the prosthetic substrates 
(alumina $50 \mu \mathrm{m}$ ) but also HF etching in LD, since it is a standard pretreatment required during luting procedures of glass-based ceramics.

The results of the current study showed that the greatest bond strength obtained with all the tested cements was achieved in LD. This was probably due to the microretention created by the use of HF etchant, which improved the surface energy for the diffusion, as well as the chemical interaction of some of such cements with the LD substrate; chemical bonds between the inorganic matrix (i.e., glass phase) and the silane contained in the self-adhesive resin cements may have been favoured in such a circumstance $[66,67]$. Indeed, the innovative self-adhesive cement PAN "Panavia SA Universal, Kuraray" showed the greatest bond strength and it was the only cement to show debond during bond strength testing in mixed mode during shear-bond testing (Table 1). Once more, these outcomes may be due to the particular composition of such a modern self-adhesive cement. In fact, unlike the self-adhesive resin cement 3M-RES, which contains MDP and a conventional silane such as methacryloxypropyl-trimethoxysilane, PAN has higher amount of MDP compared to 3M-RES, along with an innovative long carbon-chain silane coupling agent (LCSI) that, as reported by Yoshihara et al., [57], can clearly improve the adhesive of self-adhesive cements and eliminate the need for a separate primer. The LCSI is characterised by a bifunctional adhesion mechanism: (i) chemical interaction through siloxane bonds with the silica-glass phase in ceramics; (ii) copolymerisation through vinyl groups in methacrylate groups with the monomers present in the resin cements [68] However, it is important to highlight that the use of silane-coupling agents in the etched ceramic surface has been criticised when using conventional luting resin cements $[60,69]$. Conversely, we believe that the presence of a long carbon-chain silane such as LCSI within the composition of modern self-adhesive cements can be crucial to achieve a stable bond strength also after ageing. The current study reported after thermocycling aging, although all the cements showed a significant drop $(p<0.05)$ in bond strength values, that the cement PAN had the greatest bond strength values between all the tested materials. It has been reported that conventional prehydrolysed silane coupling agents in water-containing and acidic materials are often characterised by issues relative to short shelf life [70]; this may be one of the key reasons why 3M-RES had such a drastic reduction in SBS compared to PAN.

Regarding the glass ionomer cements used in this study, if one considers that both GC-GIC and 3M-GIC showed a bond strength quite low before and after TC, and with a failure mode totally occurred in adhesive mode, it is possible to suppose that due to their high viscosity there may have been an issue of infiltration of the cements into the etched LD surface; this impaired the creation of a proper micromechanical and/or chemical bonding in such a substrate [71]. However, GC-GIC is a self-curing RMGIC that takes longer than the light-curing 3M-GIC to set; according to what we previously mentioned in the zirconia substrate, GC-GIC may have created more chemical interaction with the surface of LD once stored in water environment; this may in part justify the higher baseline results observed in GC-GIC [72,73]. Conversely, the presence of water during the storage period (24 h) may have increased the sorption and solubility and hence altered the physicochemical properties of 3M-GIC [74].

Regarding the use of luting cements for the cementation of metal frameworks, the composition of the alloy and the type of the cements employed during such a phase play an important role on their retention, as well as the surface pretreatment of the prosthetic substate before luting procedures, which usually enhance the interaction between such a prosthetic substrate and cement [12]. Air-abrasion with alumina particles is the most common method used to promote such a retention, and the results of the current study confirmed that such a pretreatment of the surface of the tested alloy was able to create important microretentions (Figure 2). Also in this case, the greatest bond strength $(p<0.05)$ was attained with the self-adhesive resin cement PAN, whilst the self-adhesive 3M-RES showed the lowest bond strength between all the tested materials (Table 1 ). In addition, in this case, all the cements showed a significant drop $(p<0.05)$ in bond strength after thermocycling aging, and all specimens created using the 3M-RES cement prefailed before performing SBS testing. It has 
been reported that when $\mathrm{Ag}-\mathrm{Pd}-\mathrm{Cu}-\mathrm{Au}$ alloy restorations are cemented using self-adhesives resin cements, a quick degradation occurs at the bonding interface [14,75]. In clinical studies [76,77], it was also reported a high incidence of adhesive failure at the alloy-cement interface after a prolonged ageing period. Nevertheless, PAN showed a robust bonding performance at baseline and a more attenuated drop in SBS after thermocycling compared to all the others tested materials. This conclusion could find its support and confirmation in several studies $[78,79]$, which reported that the MDP monomer possess excellent bonding to alloys such as Ag-Pd-Cu-Au. Indeed, it was possible that the high concentration of MDP in PAN reacted chemically with Ag present in the AU alloy used in this study, so enhancing the bonding performance both at baseline and after TC ageing. Interestingly, 3M-RES contains MDP within its formulation but revealed inferior bonding ability when compared to PAN. This difference might be attributed to the different quality of MDP as well as a different concentration but also to a difference in their polymerisation initiation systems [57,70]. Therefore, in conjunction with the MDP monomer, a possible improved polymerisation may have occurred in PAN, which resulted in superior in improved bonding performance before and after TC ageing [80].

Conversely, the two glass ionomer cements tested in the current study showed comparable results and these fractured during bond strength test prevalently in adhesive mode, both at $24 \mathrm{~h}$ and after TC ageing; no significant difference between GC-GIC and PAN was observed after thermocycling. Conventional GIC cements are characterised by a week tensile strength, fracture resistance and by the absence of chemical bond with noble metal in alloys $[81,82]$. Conversely, the mechanical properties of resin-modified glass ionomer cements (RMGIC) are generally greater than those of a conventional GIC; the compressive strength of the RMGIC at $24 \mathrm{~h}$ after setting is lower than that observed in conventional resin-free GIC [83]. However, it has been supported that the polyalkenoic acids present in glass ionomer cements can react and create a chemical bond both with non-noble metals and with the passive oxide layer that usually forms on the surface of metal alloys [84,85]. Conversely, a possible explanation for the difference in bond strength between the two tested RMGICs after TC aging may be attributed to the quality of the polymerisation and water sorption, exactly the same as mentioned above for the lithium disilicate substrate.

In view of the results obtained in this study, the first null hypothesis of this study (that there would be no difference in bonding performance between tested cements when applied on different substrates) must be rejected. Moreover, the second null hypothesis that the thermocycling aging will induce no significant reduction in the SBS of the tested cements applied on different substrates must be also rejected.

\section{Conclusions}

This study demonstrated that there are significant differences in bonding performance between modern self-adhesive resin cements and conventional resin-modified glass ionomer cements when applied to prosthetic substrates such as zirconia, lithium disilicate ceramic and Au-Ag alloys. Furthermore, when such cements are submitted to thermocycling aging a strong reduction in the SBS occurs in all the tested cements. Hence, it is therefore possible to conclude that in order to achieve reliable bond strength to different prosthetic substrates that were sand-blasted with alumina, and etched with HF acid in case of glass ceramics, the use of modern universal resin luting cements containing specific functional monomers and silane would be appropriate. Such modern cements may be used for luting procedures in alloys without any metal primer application as an alternative to glass ionomer cements. However, the dental industry should place further effort in the development of such types of materials in order to generate luting cements with advanced resistance to degradation and longevity. 
Author Contributions: Conceptualization, S.S. and V.P.F.; methodology, E.P.M.; validation, S.S., A.F. and F.M.C.; formal analysis, E.P.M. and V.F.; investigation, E.P.M.; resources, S.S.; data curation, E.P.M. and S.S.; writing-original draft preparation, E.P.M. and R.M.A.; writing-review and editing, S.S., A.F. and V.C.B.L.; visualization, S.S. and A.F.; supervision, S.S. and R.M.A.; project administration, R.M.A. All authors have read and agreed to the published version of the manuscript.

Funding: This research received no external funding.

Acknowledgments: The authors gratefully acknowledge Kuraray Co. for a generous donation of the PANAVIA SA cement and Katana Zirconia substate that were used in this study. All the other materials used in this study were regularly purchased from local distributors, and for this reason the authors also acknowledge the "Programa de Consolidación de Indicadores: Fomento Plan Estatal CEU-UCH" 2019-2020 (PI: SS).

Conflicts of Interest: The authors declare no conflict of interest.

\section{References}

1. Rosenstiel, S.F.; Land, M.F.; Crispin, B.J. Dental luting agents: A review of the current literature. J. Prosthet. Dent. 1999, 80, 280-301. [CrossRef]

2. Miyahara, H.; Ikeda, H.; Fujio, Y.; Yoshii, S.; Nagamatsu, Y.; Kitamura, C.; Shimizu, H. Chemical alteration of Ag-Pd-Cu-Au alloy surface by alumina air-abrasion and its effect on bonding to resin cement. Dent. Mater. J. 2019, 38, 630-637. [CrossRef]

3. Ferracane, J.L.; Stansbury, J.W.; Burke, F.J. Self adhesive resin cements-Chemistry, properties and clinical considerations. J. Oral Rehabil. 2011, 38, 295-314. [CrossRef]

4. Manso, A.P.; Carvalho, R.M. Dental Cements for Luting and Bonding Restorations: Self-Adhesive Resin Cements. Dent. Clin. N. Am. 2017, 61, 821-834. [CrossRef] [PubMed]

5. Diaz-Arnold, A.M.; Arnold, M.A.; Williams, V.D. Measurement of water sorption by resin composite adhesives with near-infrared spectroscopy. J. Dent. Res. 1992, 71, 438-442. [CrossRef] [PubMed]

6. Christensen, G.J. How to prepare zirconia and LD e.max restorations for cementation. Clin. Rep. 2014, 6, 1-4.

7. Weiser, F.; Behr, M. Self-adhesive resin cements: A clinical review. J. Prosthodont. 2015, 24, 100-108. [CrossRef] [PubMed]

8. De la Macorra, J.C.; Pradíes, G. Conventional and adhesive luting cements. Clin. Oral Investig. 2002, 6, 198-204. [CrossRef] [PubMed]

9. Johnson, G.H.; Hazelton, L.R.; Bales, D.J.; Lepe, X. The effect of a resin-based sealer on crown retention for three types of cement. J. Prosthet. Dent. 2004, 91, 428-435. [CrossRef]

10. Schenke, F.; Hiller, K.A.; Schmalz, G.; Federlin, M. Marginal integrity of partial ceramic crowns within dentin with different luting techniques and materials. Oper. Dent. 2008, 33, 516-525. [CrossRef]

11. Toman, M.; Toksavul, S.; Sarikanat, M.; Nergiz, I.; Schmage, P. Fracture resistance of endodontically treated teeth: Effect of tooth coloured post material and surface conditioning. Eur. J. Prosthodont. Restor. Dent. 2010, 18, 23-30. [PubMed]

12. Soares, C.J.; Raposo, L.H.; Soares, P.V.; Santos-Filho, P.C.; Menezes, M.S.; Soares, P.B.; Magalhães, D. Effect of different cements on the biomechanical behavior of teeth restored with cast doweland-cores-In vitro and FEA analysis. J. Prosthodont. 2010, 19, 130-137. [CrossRef] [PubMed]

13. Krämer, N.; Lohbauer, U.; Frankenberger, R. Adhesive luting of indirect restorations. Am. J. Dent. 2000, 13, 60D-76D. [PubMed]

14. Santos, G.C., Jr.; Santos, M.J.; Rizkalla, A.S. Adhesive cementation of etchable ceramic esthetic restorations. J. Can. Dent. Assoc. 2009, 75, 379-384. [PubMed]

15. Kajihara, H.; Suzuki, S.; Minesaki, Y.; Kurashige, H.; Tanaka, T. Effect of filler loading on resin cement bonding to silanized buildup composites. Am. J. Dent. 2005, 18, 109-112.

16. D'Arcangelo, C.; De Angelis, F.; D'Amario, M.; Zazzeroni, S.; Ciampoli, C.; Caputi, S. The influence of luting systems on the microtensile bond strength of dentin to indirect resin-based composite and ceramic restorations. Oper. Dent. 2009, 34, 328-336. [CrossRef] [PubMed]

17. Taira, Y.; Soeno, K. The effect of a peroxidase primer on bond strength of three luting systems to dentin. Eur. J. Oral Sci. 2009, 117, 306-311. [CrossRef] 
18. Wolfart, M.; Lehmann, F.; Wolfart, S.; Kern, M. Durability of the resin bond strength to zirconia ceramic after using different surface conditioning methods. Dent. Mater. 2007, 23, 45-50. [CrossRef]

19. Boscato, N.; Della Bona, A.; Del Bel Cury, A.A. Influence of ceramic pre-treatments on tensile bond strength and mode of failure of resin bonded to ceramics. Am. J. Dent. 2007, 20, 103-108.

20. D'Arcangelo, C.; Vanini, L. Effect of three surface treatments on the adhesive properties of indirect composite restorations. J. Adhes. Dent. 2007, 9, 319-326.

21. Furuchi, M.; Oshima, A.; Ishikawa, Y.; Koizumi, H.; Tanoue, N.; Matsumura, H. Effect of metal priming agents on bond strength of resin-modified glass ionomers joined to gold alloy. Dent. Mater. J. 2007, 26, 728-732. [CrossRef] [PubMed]

22. Hori, S.; Minami, H.; Minesaki, Y.; Matsumura, H.; Tanaka, T. Effect of hydrofluoric acid etching on shear bond strength of an indirect resin composite to an adhesive cement. Dent. Mater. J. 2008, 27, 515-522. [CrossRef] [PubMed]

23. Taira, Y.; Kamada, K.; Atsuta, M. Effects of primers containing thiouracil and phosphate monomers on bonding of resin to Ag-Pd-Au alloy. Dent. Mater. J. 2008, 27, 69-74. [CrossRef] [PubMed]

24. Stoknorm, R.; Isidor, F.; Ravnholt, G. Tensile bond strength of resin luting cement to a porcelain-fusing noble alloy. Int. J. Prosthodont. 1996, 9, 323-330.

25. Moulin, P.; Degrange, M.; Picard, B. Influence of surface treatment on adherence energy of alloys used in bonded prosthetics. J. Oral Rehabil. 1999, 26, 413-421. [CrossRef]

26. Scherrer, S.; Cesar, P.F.; Swain, M.V. Direct comparison of the bond strength results of the different test methods: A critical literature review. Dent. Mater. 2010, 26, e78-e93. [CrossRef]

27. Van Meerbeek, B.; Peumans, M.; Poitevin, A.; Mine, A.; Van Ende, A.; Neves, A.; De Munck, J. Relationship between bond-strength tests and clinical outcomes. Dent. Mater. 2010, 26, e100-e121. [CrossRef]

28. Phrukkanon, S.; Burrow, M.F.; Tyas, M.J. The influence of cross-sectional shape and surface area on the microtensile bond test. Dent. Mater. 1998, 14, 212-221. [CrossRef]

29. Amaral, F.L.; Colucci, V.; Palma-Dibb, R.G.; Corona, S.A. Assessment of in vitro methods used to promote adhesive interface degradation: A critical review. J. Esthet. Restor. Dent. 2007, 19, 340-353. [CrossRef]

30. De Munck, J.; Van Landuyt, K.; Coutinho, E.; Poitevin, A.; Peumans, M.; Lambrechts, P.; Van Meerbeek, B. Micro-tensile bond strength of adhesives bonded to Class-I cavity-bottom dentin after thermo-cycling. Dent. Mater. 2005, 21, 999-1007. [CrossRef]

31. Gale, M.S.; Darvell, B.W. Thermal cycling procedures for laboratory testing of dental restorations. J. Dent. 1999, 27, 89-99. [CrossRef]

32. Raigrodski, A.J.; Hillstead, M.B.; Meng, G.K.; Chung, K.H. Survival and complications of zirconia-based fixed dental prostheses: A systematic review. J. Prosthet. Dent. 2012, 107, 170-177. [CrossRef]

33. Marshall, S.J.; Bayne, S.C.; Baier, R.; Tomsia, A.P.; Marshall, G.W. A review of adhesion science. Dent. Mater. 2010, 26, e11-e16. [CrossRef] [PubMed]

34. Liu, D.; Tsoi, J.K.; Matinlinna, J.P.; Wong, H.M. Effects of some chemical surface modifications on resin zirconia adhesion. J. Mech. Behav. Biomed. Mater. 2015, 46, 23-30. [CrossRef] [PubMed]

35. Casucci, A.; Monticelli, F.; Goracci, C.; Mazzitelli, C.; Cantoro, A.; Papacchini, F.; Ferrari, M. Effect of surface pre-treatments on the zirconia ceramic-resin cement microtensile bond strength. Dent. Mater. 2011, 27, 1024-1030. [CrossRef]

36. Yang, L.; Xie, H.; Meng, H.; Wu, X.; Chen, Y.; Zhang, H.; Chen, C. Effects of Luting Cements and Surface Conditioning on Composite Bonding Performance to Zirconia. J. Adhes. Dent. 2018, 20, 549-558.

37. Piwowarczyk, A.; Lauer, H.C.; Sorensen, J.A. In vitro shear bond strength of cementing agents to fixed prosthodontic restorative materials. J. Prosthet. Dent. 2004, 92, 265-273. [CrossRef]

38. Capa, N.; Özkurt, Z.; Canpolat, C.; Kazazoglu, E. Shear bond strength of luting agents to fixed prosthodontic restorative core materials. Aust. Dent. J. 2009, 54, 334-340. [CrossRef]

39. Yoshida, K.; Tsuo, Y.; Atsuta, M. Bonding of dual-cured resin cement to zirconia ceramic using phosphate acid ester monomer and zirconate coupler. J. Biomed. Mater. Res. B Appl. Biomater. 2006, 77, 28-33. [CrossRef]

40. Gomes, A.L.; Castillo-Oyagüe, R.; Lynch, C.D.; Montero, J.; Albaladejo, A. Influence of sandblasting granulometry and resin cement composition on microtensile bond strength to zirconia ceramic for dental prosthetic frameworks. J. Dent. 2013, 41, 31-41. [CrossRef] 
41. Özcan, M.; Bernasconi, M. Adhesion to zirconia used for dental restorations: A systematic review and meta-analysis. J. Adhes. Dent. 2015, 17, 7-26. [PubMed]

42. Kitayama, S.; Nikaido, T.; Takahashi, R.; Zhu, L.; Ikeda, M.; Foxton, R.M.; Sadr, A.; Tagami, J. Effect of primer treatment on bonding of resin cements to zirconia ceramic. Dent. Mater. 2010, 26, 426-432. [CrossRef] [PubMed]

43. Koizumi, H.; Nakayama, D.; Komine, F.; Blatz, M.B.; Matsumura, H. Bonding of resin-based luting cements to zirconia with and without the use of ceramic priming agents. J. Adhes. Dent. 2012, 14, 385-392. [PubMed]

44. Xie, H.; Tay, F.R.; Zhang, F.; Lu, Y.; Shen, S.; Chen, C. Coupling of 10-methacryloyloxydecyldihydrogenphosphate to tetragonal zirconia: Effect of $\mathrm{pH}$ reaction conditions on coordinate bonding. Dent. Mater. 2015, 31, e218-e225. [CrossRef]

45. Chen, L.; Suh, B.I.; Brown, D.; Chen, X. Bonding of primed zirconia ceramics: Evidence of chemical bonding and improved bond strengths. Am. J. Dent. 2012, 25, 103-108.

46. Kim, M.J.; Kim, Y.K.; Kim, K.H.; Kwon, T.Y. Shear bond strengths of various luting cements to zirconia ceramic: Surface chemical aspects. J. Dent. 2011, 39, 795-803. [CrossRef]

47. Pilo, R.; Kaitsas, V.; Zinelis, S.; Eliades, G. Interaction of zirconia primers with yttria-stabilized zirconia surfaces. Dent. Mater. 2016, 32, 353-362. [CrossRef]

48. Berzins, D.W.; Abey, S.; Costache, M.C.; Wilkie, C.A.; Roberts, H.W. Resin-modified glass-ionomer setting reaction competition. J. Dent. Res. 2010, 89, 82-86. [CrossRef]

49. Sabatini, C.; Patel, M.; D'Silva, E. In vitro shear bond strength of three self-adhesive resin cements and a resin-modified glass ionomer cement to various prosthodontic substrates. Oper. Dent. 2013, 38, 186-196. [CrossRef]

50. Wan, A.C.A.; Yap, A.U.J.; Hastings, G.W. Acid-base complex reactions in resin-modified and conventional glass ionomer cements. J. Biomed. Mater. Res. 1999, 48, 700-704. [CrossRef]

51. Young, A.M.; Rafeeka, S.A.; Howlett, J.A. FTIR investigation of monomer polymerisation and polyacid neutralisation kinetics and mechanisms in various aesthetic dental restorative materials. Biomaterials 2004, 25, 823-833. [CrossRef]

52. Wegner, S.M.; Gerdes, W.; Kern, M. Effect of different artificial aging conditions on ceramic-composite bond strength. Int. J. Prosthodont. 2002, 15, 267-272. [PubMed]

53. Blatz, M.B.; Chiche, G.; Holst, S.; Sadan, A. Influence of surface treatment and simulated aging on bond strengths of luting agents to zirconia. Quintessence Int. 2007, 38, 745-753. [PubMed]

54. Marchan, S.; Coldero, L.; Whiting, R.; Barclay, S. In vitro evaluation of the retention of zirconia-based ceramic posts luted with glass ionomer and resin cements. Braz. Dent. J. 2005, 3, 213-217. [CrossRef] [PubMed]

55. Lüthy, H.; Loeffel, O.; Hammerle, C.H. Effect of thermocycling on bond strength of luting cements to zirconia ceramic. Dent. Mater. 2006, 22, 195-200. [CrossRef]

56. Inokoshi, M.; De Munck, J.; Minakuchi, S.; Van Meerbeek, B. Meta-analysis of bonding effectiveness to zirconia ceramics. J. Dent. Res. 2014, 93, 329-334. [CrossRef]

57. Nagaoka, N.; Yoshihara, K.; Feitosa, V.P.; Tamada, Y.; Irie, M.; Yoshida, Y.; Van Meerbeek, B.; Hayakawa, S. Chemical interaction mechanism of 10-MDP with zirconia. Sci. Rep. 2017, 7, 45563. [CrossRef]

58. Yoshihara, K.; Nagaoka, N.; Maruo, Y.; Nishigawa, G.; Yoshida, Y.; Van Meerbeek, B. Silane-coupling effect of a silane-containing self-adhesive composite cement. Dent. Mater. 2020, 36, 914-926. [CrossRef]

59. Aboushelib, M.N.; Sleem, D. Microtensile bond strength of lithium disilicate ceramics to resin adhesives. J. Adhes. Dent. 2014, 16, 547-552.

60. Özcan, M.; Vallittu, P.K. Effect of surface conditioning methods on the bond strength of luting cement to ceramics. Dent. Mater. 2003, 19, 725-731. [CrossRef]

61. Della Bona, A.; Shen, C.; Anusavice, K.J. Work of adhesion of resin on treated lithia disilicate based ceramic. Dent. Mater. 2004, 20, 338-344. [CrossRef]

62. Ramakrishnaiah, R.; Alkheraif, A.A.; Divakar, D.D.; Matinlinna, J.P.; Vallittu, P.K. The effect of hydrofluoric acid etching duration on the surface micromorphology, roughness, and wettability of dental ceramics. Int. J. Mol. Sci. 2016, 17, 822. [CrossRef]

63. Lise, D.P.; Perdigao, J.; Van Ende, A.; Zidan, O.; Lopes, G.C. Microshear Bond Strength of Resin Cements to Lithium Disilicate Substrates as a Function of Surface Preparation. Oper. Dent. 2015, 40, 524-532. [CrossRef] 
64. Attia, A. Influence of surface treatment and cyclic loading on the durability of repaired allceramic crowns. J. Appl. Oral Sci. 2010, 18, 194-200. [CrossRef] [PubMed]

65. Ayad, M.F.; Fahmy, N.Z.; Rosenstiel, S.F. Effect of surface treatment on roughness and bond strength of a heat-pressed ceramic. J. Prosthet. Dent. 2008, 99, 123-130. [CrossRef]

66. Guarda, G.B.; Correr, A.B.; Gonçalves, L.S.; Costa, A.R.; Borges, G.A.; Sinhoreti, M.A.; Correr-Sobrinho, L. Effects of surface treatments, thermocycling, and cyclic loading on the bond strength of a resin cement bonded to a lithium disilicate glass ceramic. Oper. Dent. 2013, 38, 208-217. [CrossRef]

67. Della Bona, A.; Anusavice, K.J. Microstructure, composition, and etching topography of dental ceramics. Int. J. Prosthodont. 2002, 15, 159-167.

68. Tian, T.; Tsoi, J.K.; Matinlinna, J.P.; Burrow, M.F. Aspects of bonding between resin luting cements and glass ceramic materials. Dent. Mater. 2014, 30, e147-e162. [CrossRef]

69. Matinlinna, J.P.; Lassila, L.V.; Özcan, M.; Yli-Urpo, A.; Vallittu, P.K. An introduction to silanes and their clinical applications in dentistry. Int. J. Prosthodont. 2004, 17, 155-164.

70. Oliveira, A.S.; Ramalho, E.S.; Ogliari, F.A.; Moraes, R.R. Bonding self-adhesive resin cements to glass fibre posts: To silanate or not silanate? Int. Endod. J. 2011, 44, 759-763. [CrossRef]

71. Yoshihara, K.; Nagaoka, N.; Sonoda, A.; Maruo, Y.; Makita, Y.; Okihara, T.; Irie, M.; Yoshida, Y.; Van Meerbeek, B. Effectiveness and stability of silane coupling agent incorporated in 'universal' adhesives. Dent. Mater. 2016, 32, 1218-1225. [CrossRef] [PubMed]

72. Van den Breemer, C.R.; Gresnigt, M.M.; Cune, M.S. Cementation of Glass-Ceramic Posterior Restorations: A Systematic Review. Biomed. Res. Int. 2015, 2015, 148954. [CrossRef] [PubMed]

73. Prakki, A.; Cilli, R.; Mondelli, R.F.; Kalachandra, S.; Pereira, J.C. Influence of Ph environment on polymer based dental material properties. J. Dent. 2005, 33, 91-98. [CrossRef] [PubMed]

74. Gerdolle, D.A.; Mortier, E.; Jacquot, B.; Panighi, M.M. Water sorption and water solubility of current luting cements: An in vitro study. Quintessence Int. 2008, 39, e107-e114.

75. Yap, A.; Lee, C.M. Water sorption and solubility of resin-modified polyalkenoate cements. J. Oral Rehabil. 1997, 24, 310-314. [CrossRef]

76. Abreu, A.; Loza, M.A.; Elias, A.; Mukhopadhyay, S.; Looney, S.; Rueggeberg, F.A. Tensile bond strength of an adhesive resin cement to different alloys having various surface treatments. J. Prosthet. Dent. 2009, 101, 107-118. [CrossRef]

77. Hikage, S.; Hirose, Y.; Sawada, N.; Endo, K.; Ohno, H. Clinical longevity of resin-bonded bridges bonded using a vinyl-thiol primer. J. Oral Rehabil. 2003, 30, 1022-1029. [CrossRef]

78. Hansson, O.; Bergström, B.A. Longitudinal study of resin-bonded prostheses. J. Prosthet. Dent. 1996, 76, 132-139. [CrossRef]

79. Almilhatti, H.J.; Giampaolo, E.T.; Vergani, C.E.; Machado, A.L.; Pavarina, A.C.; Betiol, E.A. Adhesive bonding of resin composite to various $\mathrm{Ni}-\mathrm{Cr}$ alloy surfaces using different metal conditioners and a surface modification system. J. Prosthodont. 2009, 18, 663-669. [CrossRef]

80. Masuno, T.; Koizumi, H.; Ishikawa, Y.; Nakayama, D.; Yoneyama, T.; Matsumura, H. Effect of acidic monomers on bonding to SUS XM27 stainless steel, iron, and chromium with a tri-nbutylborane-initiated acrylic resin. J. Adhes. Dent. 2011, 13, 163-169.

81. Muraguchi, K.; Minami, H.; Minesaki, Y.; Suzuki, S.; Tanaka, T. A study of self-adhesive resin cements for bonding to silver-palladium-copper-gold alloy-Effect of including primer components in cement base. Dent. Mater. J. 2011, 30, 199-205. [CrossRef] [PubMed]

82. Orsi, I.A.; Varoli, F.K.; Pieroni, C.H.; Ferreira, M.C.; Borie, E. In vitro tensile strength of luting cements on metallic substrate. Braz. Dent. J. 2014, 25, 136-140. [CrossRef] [PubMed]

83. Ozer, F.; Pak-Tunc, E.; Esen Dagli, N.; Ramachandran, D.; Sen, D.; Blatz, M.B. Shear bond strength of luting cements to fixed superstructure metal surfaces under various seating forces. J. Adv. Prosthodont. 2018, 10, 340-346. [CrossRef] [PubMed] 
84. Lim, H.N.; Kim, S.H.; Yu, B.; Lee, Y.K. Influence of HEMA content on the mechanical and bonding properties of experimental HEMA-added glass ionomer cements. J. Appl. Oral Sci. 2009, 17,340-349. [CrossRef] [PubMed]

85. Hibino, Y.; Kuramochi, K.; Hoshino, T.; Moriyama, A.; Watanabe, Y.; Nakajima, H. Relationship between the strength of glass ionomers and their adhesive strength to metals. Dent. Mater. 2002, 18, 552-557. [CrossRef]

Publisher's Note: MDPI stays neutral with regard to jurisdictional claims in published maps and institutional affiliations.

(C) 2020 by the authors. Licensee MDPI, Basel, Switzerland. This article is an open access article distributed under the terms and conditions of the Creative Commons Attribution (CC BY) license (http://creativecommons.org/licenses/by/4.0/). 